\title{
Controle da eficácia de bacterinas antileptospirose: relação entre os resultados dos testes de inibição de crescimento de leptospiras in vitro com os do desafio in vivo em hamsters
}

\author{
Efficacy of anti-leptospirosis bacterines. Relation between the results of the in vitro growth \\ inhibition test and the potency test, in vivo, with challenge in hamsters
}

\author{
Amane Paldês GONÇALES ${ }^{1}$; Gisele Oliveira de SOUZA²; Flávia MORATO²; \\ Zenaide Maria de MORAIS ${ }^{2}$; Sérgio Santos AZEVEDO ${ }^{3}$; Silvio Arruda VASCONCELLOS ${ }^{2}$ \\ ${ }^{1}$ Universidade de Santo Amaro, São Paulo - SP, Brasil \\ ${ }^{2}$ Universidade de São Paulo, São Paulo - SP, Brasil \\ ${ }^{3}$ Universidade Federal de Campina Grande, Campina Grande - PB, Brasil
}

\begin{abstract}
Resumo
Foi efetuada a comparação em hamsters da proteção conferida e dos níveis de anticorpos induzidos por duas bacterinas comerciais antileptospirose. Os ensaios empregados foram o teste oficial de potência com desafio (TP), o ensaio proposto, teste de inibição de crescimento de leptospiras in vitro (ICLIV) e a soroaglutinação microscópica (SAM). O protocolo de imunização foi representado por duas aplicações individuais de $0,25 \mathrm{~mL}$ das bacterinas, puras ou de suas diluições geométricas de razão dois variando de 200 a 51.200 para a bacterina A e de 200 a 3.200 para a bacterina $\mathrm{B}$, por via subcutânea com o intervalo de 15 dias. Decorridos 15 dias da segunda aplicação de vacina, um grupo de animais foi desafiado com $0,2 \mathrm{~mL}$ de cultivos de leptospiras, por indivíduo, respectivamente dos sorovares Canicola (bacterinas A e B) ou Kennewicki (bacterina A). Os números de doses infectantes empregados nos desafios foram de 100 e 631 respectivamente, para os sorovares Canicola e Kennewicki. Decorridos 21 dias do desafio, os grupos de animais utilizados nos testes de ICLIV e SAM foram sangrados e os seus soros foram reunidos em pools $(\mathrm{n}=5)$. No TP, adotando-se os critérios internacionais, as bacterinas foram aprovadas. A comparação do desempenho das bacterinas para os sorovares adotados, segundo sua concentração, por meio das proporções de animais sobreviventes ao TP e a média dos títulos de anticorpos identificados no teste de ICLIV, indicou que um título igual ou superior a 0,77 log corresponde ao nível de aprovação da bacterina no TP.
\end{abstract}

Palavras-chave: Leptospirose animal. Hamsteres. Vacinas. Teste de potência. Teste de inibição de crescimento in vitro.

\begin{abstract}
It was performed a comparison between the protection afforded in hamsters and the antibody levels induced by two commercial vaccines against leptospirosis. The assays used were the official challenge test (TP), the in vitro leptospires growth inhibition test (ICLIV) and microscopic agglutination test (MAT). The immunization protocol consisted of two single applications, 15 days from each other, of $0.25 \mathrm{~mL}$ of the bacterins, pure or its two-fold serial dilutions: 200 to 51,200 for bacterin A and 200 to 3.200 bacterin B, both of them administered subcutaneously. A group of animals was challenged, after 15 days from the second vaccine application, with $0.2 \mathrm{~mL} /$ animal of live leptospire cultures, with Canicola (bacterin A and B) or Kennewicki (bacterin A) serovars. The numbers of infective doses employed in the challenges were 100 and 631 for Canicola and Kennewicki serovars, respectively. After 15 days from the second vaccine dose the groups of animals used in ICLIV and SAM tests were bled and their sera were collected in pools $(n=5)$. In TP, adopting the criteria established by the Code Federal Regulation, both bacterins were approved. The comparison of the performance of the tested bacterins with the adopted serovars, according to its concentration, by the proportions of surviving animals to the challenge assay and the average of the neutralizing antibodies titers, established a neutralizing antibodies titer equal or higher than $0.77 \log$ corresponding with the bacterin level of approval in the potency assay.
\end{abstract}

Keywords: Animal leptospirosis. Hamsters. Vaccines. Potency text. In vitro growth inibition test and potency.

Correspondência para:

Amane Paldês Gonçales

Faculdade de Medicina Veterinária da Universidade de Santo Amaro (UNISA)

Rua Professor Enéas de Siqueira Neto, 340, Jardim das Imbuias
CEP 04829-300, São Paulo, SP, Brasil

E-mail: manipaldes@yahoo.com.br

Recebido: $12 / 08 / 2013$

Aprovado: 24/10/2013 


\section{Introdução}

O hamster (Mesocricetus auratus) tem sido o modelo biológico de escolha para a avaliação da eficácia de vacinas antileptospirose em testes de potência (UNITED STATES OF AMERICA, 2006a,b). As maiores desvantagens apontadas para a realização desse teste incluem: grande número de animais utilizados, dificuldade para manutenção da virulência das amostras de desafio e alto risco de infecção acidental dos manipuladores (MARBEHANT, 1999). O Code Federal Regulation (UNITED STATES OF AMERICA, 2006a,b) e a OIE (OFFICE INTERNATIONAL DES EPIZOOTIES, 2008) recomendam o emprego do teste de desafio em hamsters ou cobaias jovens com os sorovares incluídos na vacina. Esses protocolos estabelecem que nos hamsters a vacina deve ser testada na diluição de 1/800 da dose estipulada para uso em bovinos ou suínos.

O teste de inibição do crescimento de leptospiras in vitro, ICLIV (TRIPATHY; HANSON; KRUMREY, 1971; TRIPATHY; HANSON; MANSFIELD, 1973), avalia a concentração de anticorpos neutralizantes, protetores, presentes no soro sanguíneo de animais vacinados, que usualmente não apresenta relação direta com a concentração de anticorpos aglutinantes revelados pelo teste clássico de soroaglutinação microscópica, SAM (HANSON, 1977). Hanson (1977) relatou que em tais procedimentos as classes de anticorpos predominantes são distintas, com participação prioritária de IgM ou IgG, respectivamente para SAM e ICLIV.

Em ensaios de campo, a proteção conferida por bacterinas comerciais antileptospirose não foi capaz de eliminar o estado de portador renal de leptospiras. O poder imunogênico dessas bacterinas foi reduzido e os títulos de anticorpos pós-vacinais, revelados pelo teste de SAM, foram baixos e de curta duração (LEVETT, 2001; ARDUINO et al., 2004). Tais observações ressaltam a necessidade da intensificação dos cuidados com os procedimentos atualmente empregados para o controle de qualidade dessas bacterinas.

A despeito do ICLIV já ter sido empregado em diversos experimentos (TABATA et al., 2002; SOTO et al., 2008; NARDI JUNIOR et al., 2010; RODRIGUES et al., 2013), até o presente ainda não foi realizada uma análise da correlação existente entre os seus resultados com os obtidos no teste oficial de potência de vacinas antileptospirose com desafio em hamsters.

O presente trabalho teve por objetivo o estabelecimento de uma relação entre os resultados dos testes de inibição de crescimento de leptospiras in vitro, com o oficial de desafio in vivo em hamsters incluindo também a análise do estado de portador renal de leptospiras nos animais vacinados que sobreviveram ao desafio.

\section{Materiais e Métodos}

Foram utilizadas bacterinas comerciais polivalentes, designadas pelas letras A e B, produzidas para uso em bovinos e suínos, contendo os sorovares Pomona, Icterohaemorrhagiae, Canicola, Hardjo, Grippothyphosa e Bratislava. A bacterina B também possuía o sorovar Tarassovi em sua formulação.

Os animais empregados foram hamsters (Mesocricetus auratus), machos jovens, com 60 a 100 gramas de peso vivo.

Nos testes de potência das bacterinas A e B, os animais foram distribuídos, respectivamente, em doze e oito grupos de dez animais, por sorovar utilizado no desafio. Para cada bacterina houve um grupo controle ambiental não vacinado e não desafiado, tratado com duas aplicações de $0,25 \mathrm{~mL}$ de solução salina estéril $0,85 \%$, via subcutânea, com intervalo de 15 dias; grupos controle por sorovar de desafio, não vacinado e desafiado, tratados com duas aplicações de $0,25 \mathrm{~mL}$ de solução salina estéril $0,85 \%$, via subcutânea, com intervalo de 15 dias.

A bacterina A foi aplicada em dez grupos de animais vacinados com duas aplicações de $0,25 \mathrm{~mL}$ da bacterina, por via subcutânea, com intervalo de 15 dias, cada um deles foi tratado com uma concentração distinta da vacina: pura ou diluída em uma série de diluições geométricas de razão dois variando de 200 a 51.200.

A bacterina B foi aplicada em seis grupos de animais vacinados com duas aplicações de $0,25 \mathrm{~mL}$ da vacina, 
por via subcutânea, com intervalo de 15 dias, cada um deles foi tratado com uma concentração distinta da vacina: pura ou diluída em uma série de diluições geométricas de razão dois variando de 200 a 3.200.

Decorridos 21 dias da segunda aplicação das vacinas, com exceção dos grupos de controle ambiental, os animais foram desafiados com o volume individual de 0,2 $\mathrm{mL}$, por via intraperitonial, de culturas vivas dos sorovares Kennewicki ou Canicola (bacterina A) ou apenas Kennewicki (bacterina B).

Os desafios dos testes de potência foram efetuados com suspensão em meio de cultivo de EMJH do tecido hepático colhido de hamsters experimentalmente infectados com os sorovares Kennewicki estirpe Pomona Fromm (LPF) ou Canicola estirpe LO4 comprovadamente patogênicas para estes animais (TABATA et al., 2002; COELHO et al., 2013, RODRIGUES et al., 2013). A diluição escolhida para o desafio foi a $10^{-6}$, que correspondeu a três diluições superiores à maior diluição em que foi possível a contagem de 10 a 20 leptospiras por campo microscópico em microscopia de campo escuro (UNITED STATES OF AMERICA, 2006a,b).

O controle do número de doses infectantes efetivamente empregadas nos inóculos de desafio foi realizado com uma série diluições em escala geométrica de razão dez $\left(10^{-5}\right.$ a $\left.10^{-12}\right)$ por sorovar, utilizando cinco animais por diluição com o volume de $0,2 \mathrm{~mL} /$ hamster, via intraperitonial. Os animais foram observados diariamente durante 21 dias, com retirada dos mortos por leptospirose. $\mathrm{O}$ cálculo da $\mathrm{DL}_{50}$ foi efetuado através do método de Reed e Müench (1938).

Os animais vacinados foram observados por 21 dias pós-infecção, e ao final deste período os sobreviventes ao desafio foram submetidos à eutanásia por inalação de gás carbônico e necropsiados para colheita dos rins e realização de cultivos em meio de Fletcher, destinados ao controle da presença de infecção renal por leptospiras (COELHO et al., 2013).

Os níveis de aglutininas antileptospiras dos pools de soros dos hamsteres foram avaliados utilizando-se a técnica de soroaglutinação microscópica com antígenos vivos (SAM) (FAINE et al., 1999) frente aos sorovares Canicola e Kennewicki. O ponto de corte da reação foi a diluição de 1:100. O título considerado foi a recíproca da maior diluição do soro que apresentou $50 \%$ de leptospiras aglutinadas.

A mensuração dos níveis de anticorpos neutralizantes foi efetuada com o emprego do teste ICLIV adaptado da descrição de Triphaty et al. (1973) e ajustado para as condições do laboratório (TABATA et al., 2002).

As imunizações dos animais destinados ao teste de ICLIV para as vacinas A e B seguiram o mesmo esquema descrito para o teste de potência; no entanto, decorridos 15 dias da última vacinação, os animais foram anestesiados por inalação de gás carbônico, sangrados assepticamente por meio de punção intracardíaca para a obtenção de soro destinado à ICLIV e SAM e, posteriormente, sacrificados em câmara de gás carbônico. Cada grupo foi distribuído em dois subgrupos, destinados ao preparo dos pools de soros $(\mathrm{n}=5)$. Os pools de soros obtidos foram inativados a $56^{\circ} \mathrm{C}$ por 40 minutos e diluídos em escala geométrica de razão dois (1:2 a 1:32) em solução salina tamponada de Sorensen. Para cada diluição de soro foram utilizadas cinco repetições em tubos contendo 2,5 mL de meio EMJH modificado (ALVES et al., 1996), 0,2 mL do soro a ser testado e 0,1 $\mathrm{mL}$ de cultura de leptospiras vivas, sorovares Canicola ou Kennewicki com dez dias de cultivo. Os tubos foram incubados em estufa a $28-30^{\circ} \mathrm{C}$ por dez dias. Após esse período foram examinados para a observação de presença ou ausência de crescimento de leptospiras pela turvação macroscópica subsuperficial (MYERS, 1985). A avaliação do crescimento foi realizada pela escala de turbidez que variou de 0 a 4 . Os tubos que não apresentaram nenhum crescimento ou atingiram no máximo o valor 2 na escala de turvação foram considerados positivos para anticorpos neutralizantes, responsáveis pela inibição de crescimento das leptospiras. Os tubos que apresentaram turbidez ou crescimento na escala variando de 3 a 4 foram considerados negativos para anticorpos inibidores de crescimento 
de leptospiras. A composição dos pools de soros foi adotada, pois o volume máximo de soro sanguíneo obtido individualmente por hamster foi insuficiente para a realização da prova.

O resultado do teste de potência das vacinas nos hamsters foi analisado pelo critério preconizado pelo teste de potência para bacterinas de Leptospira interrogans, proposto pelo American Code Federal Regulation - CFR 113.101, sorovar Pomona, e CFR 113.103 sorovar Canicola (UNITED STATES OF AMERICA, 2006a,b).

A diluição nos pools dos soros dos hamsters, capaz de inibir o crescimento de leptospiras em 50\% dos tubos, foi calculada pelo método de Reed e Müench (1938), e os intervalos de confiança (95\%) dos títulos de anticorpos neutralizantes antileptospiras foram calculados conforme Pizzi (1950).

O trabalho foi analisado e aprovado pelo Comitê de Bioética da Faculdade de Medicina Veterinária e Zootecnia da Universidade de São Paulo, protocolo n ${ }^{\circ}$ $765 / 205$.

\section{Resultados}

Os resultados do teste de desafio em hamsters com as bacterinas comerciais antileptospirose A e
B, apresentados na Tabela 1, estão dentro dos parâmetros exigidos, segundo os critérios internacionais de controle de qualidade de vacinas antileptospirose (UNITED STATES OF AMERICA, 2006a,b) que é de $80 \%(8 / 10)$ de animais sobreviventes na diluição da bacterina recomendada para hamsters, diluída 1:800 da dose recomendada para bovinos e suínos e de no máximo 20\% (2/10) de sobreviventes no grupo controle não vacinado. $\mathrm{O}$ número de sobreviventes imunizados com a bacterina A ficou dentro dos critérios mínimos exigidos para aprovação $80 \%(8 / 10)$ até as diluições 1:12.800 e 1:1.600 quando desafiada, respectivamente, com os sorovares Canicola e Kennewicki. A proporção de mortes para a bacterina B permaneceu dentro dos 20\% permitidos até a diluição 1:800.

$\mathrm{O}$ número de $\mathrm{DL}_{50}$ efetivamente empregado foi de 100 para o sorovar Canicola e de 631 para o sorovar Kennewicki. As $\mathrm{DL}_{50}$ empregadas nos experimentos estão de acordo com os valores estabelecidos pelas CFR 113.101 e 113.103, que admitem a faixa de variação de 10 a $10.000 \mathrm{DL}_{50}$.

Na Tabela 2 são observadas as proporções de hamsters sobreviventes ao desafio com os sorovares Canicola ou Kennewicki vacinados com as bacterinas A ou B, puras ou com as suas diluições, que apresentaram

Tabela 1 - Proporção de hamsters vacinados contra a leptospirose com as bacterinas comerciais A e B, sobreviventes ao desafio segundo a diluição da bacterina e o sorovar de leptospira empregado para o desafio - São Paulo - 2013

\begin{tabular}{|c|c|c|c|}
\hline \multirow{3}{*}{$\begin{array}{l}\text { Diluição das } \\
\text { bacterinas }\end{array}$} & \multicolumn{2}{|c|}{ Vacina A } & \multirow[t]{2}{*}{ Vacina B } \\
\hline & \multicolumn{2}{|c|}{ Sorovar de desafio } & \\
\hline & Canicola & Kennewicki & Canicola \\
\hline Pura & $10 / 10^{*}$ & $10 / 10^{\star}$ & $10 / 10^{*}$ \\
\hline $1: 200$ & $10 / 10$ & $10 / 10$ & $10 / 10$ \\
\hline $1: 400$ & $10 / 10$ & $10 / 10$ & $10 / 10$ \\
\hline $1: 800^{* *}$ & $10 / 10$ & $10 / 10$ & $8 / 10$ \\
\hline $1: 1.600$ & $10 / 10$ & $10 / 10$ & $4 / 10$ \\
\hline $1: 3.200$ & $9 / 10$ & $07 / 10$ & $0 / 10$ \\
\hline $1: 6.400$ & $10 / 10$ & $9 / 10$ & $\ldots$ \\
\hline $1: 12.800$ & $08 / 10$ & $6 / 10$ & $\ldots$ \\
\hline $1: 25.600$ & $6 / 10$ & $5 / 10$ & $\ldots$ \\
\hline $1: 51.200$ & $3 / 10$ & $4 / 10$ & $\ldots$ \\
\hline Controle ${ }^{* * *}$ & $1 / 10$ & $0 / 10$ & $1 / 10$ \\
\hline
\end{tabular}

*Número de sobreviventes/número de animais desafiados.

**Diluição considerada como padrão para a aprovação de bacterina CFR 113.101e 113.103 (UNITED STATES OF AMERICA, 2006).

***Solução salina $0,85 \%$.

... Dados inexistentes. 
estado de portador renal, confirmado pelo isolamento de leptospiras nos cultivos de tecido renal em meio semissólido de Fletcher. A diluição 1:800 das duas bacterinas testadas, estabelecida pelas normas internacionais, não foi capaz de proteger os animais contra o estado de portador renal de leptospiras, pois um hamster vacinado com cada bacterina diluída 1:400 e desafiado com o sorovar Canicola apresentou infecção renal por leptospiras por este sorovar (1/10), no entanto, o mesmo não ocorreu com a bacterina $\mathrm{A}$ quando desafiada com o sorovar Kennewicki.

$\mathrm{Na}$ Tabela 3 são apresentados os intervalos de confiança (95\%) das médias geométricas dos títulos de anticorpos neutralizantes dos pools dos soros de hamsteres vacinados com as bacterinas polivalentes antileptospirose A e B, segundo a concentração da bacterina e o sorovar testado. Os pools dos soros dos animais do grupo controle, não vacinados, foram não reagentes ao teste de ICLIV para os sorovares Canicola e Kennewicki, o que confirmou a especificidade do teste.

Tabela 2 - Proporção de hamsters vacinados contra a leptospirose com as bacterinas A e B, sobreviventes ao desafio e caracterizados como portadores renais de leptospiras, segundo a concentração das bacterinas e sorovar de leptospira empregado para o desafio - São Paulo - 2013

\begin{tabular}{lccc}
\hline \multirow{2}{*}{$\begin{array}{l}\text { Concentração das } \\
\text { bacterinas }\end{array}$} & \multicolumn{2}{c}{ Vacina A } & Vacina B \\
\cline { 2 - 4 } & Canicola & Sorovar de desafio & Canicola \\
\cline { 2 - 4 } & $0 / 10^{*}$ & $0 / 10^{*}$ & $0 / 10^{*}$ \\
\hline Pura & $0 / 10$ & $0 / 10$ & $0 / 10$ \\
$1: 200$ & $1 / 10$ & $0 / 10$ & $1 / 10$ \\
$1: 400$ & $0 / 10$ & $0 / 10$ & $0 / 8$ \\
$1: 800^{* *}$ & $0 / 10$ & $0 / 10$ & $0 / 4$ \\
$1: 1.600$ & $3 / 09$ & $0 / 7$ & $\ldots$ \\
$1: 3.200$ & $2 / 10$ & $0 / 9$ & $\ldots$ \\
$1: 6.400$ & $2 / 8$ & $0 / 6$ & $\ldots$ \\
$1: 12.800$ & $1 / 6$ & $1 / 5$ & $\ldots$ \\
$1: 25.600$ & $0 / 3$ & $1 / 4$ & $\ldots$ \\
$1: 51.200$ & & & $\ldots$ \\
\hline
\end{tabular}

${ }^{*}$ Número de portadores renais/número de animais sobreviventes ao desafio.

**Diluição considerada como padrão para a aprovação de bacterina CFR 113.101 (UNITED STATES OF AMERICA, 2006).

... Dados inexistentes.

Tabela 3 - Títulos de anticorpos neutralizantes antileptospiras e o respectivo intervalo de confiança (IC 95\%) expressos em logaritmo de base 10 para o sorovar Canicola ou Kennewicki, em pools dos soros dos hamsters imunizados com as bacterinas A e B antileptospirose, segundo a concentração das bacterinas - São Paulo - 2013

\begin{tabular}{lccc}
\hline \multirow{2}{*}{$\begin{array}{l}\text { Concentração das } \\
\text { bacterinas }\end{array}$} & \multicolumn{3}{c}{ Anticorpos neutralizantes e IC (95\%) } \\
\cline { 2 - 4 } & Canicola & Vacina A & Vacina B \\
\cline { 2 - 4 } & $1,324 \pm 0,272$ & $1,266 \pm 0,284$ & $1,108 \pm 0,323$ \\
$1: 200$ & $1,260 \pm 0,307$ & $1,279 \pm 0,299$ & $1,036 \pm 0,305$ \\
$1: 400$ & $1,204 \pm 0,283$ & $1,232 \pm 0,303$ & $1,016 \pm 0,281$ \\
$1: 800^{*}$ & $1,180 \pm 0,265$ & $1,118 \pm 0,337$ & $1,096 \pm 0,326$ \\
$1: 1.600$ & $1,204 \pm 0,286$ & $1,212 \pm 0,260$ & $0,877 \pm 0,352$ \\
$1: 3.200$ & $1,173 \pm 0,299$ & $0,920 \pm 0,312$ & $\ldots$ \\
$1: 6.400$ & $1,030 \pm 0,293$ & $1,168 \pm 0,336$ & $\ldots$ \\
$1: 12.800$ & $0,980 \pm 0,331$ & $0,870 \pm 0,300$ & $\ldots$ \\
$1: 25.600$ & $0,839 \pm 0,344$ & $0,903 \pm 0,307$ & $\ldots$ \\
$1: 51.200$ & $0,646 \pm 0,322$ & $0,953 \pm 0,321$ & \\
Controle & $0,0 \pm 0,0$ & $0,0 \pm 0,0$ & \\
\hline
\end{tabular}

*Diluição considerada como padrão para a aprovação de bacterina CFR 113.101 e 113.103 (UNITED STATES OF AMERICA, 2006).

${ }^{*}$ Solução salina $0,85 \%$.

... Dados inexistentes. 
$\mathrm{Na}$ Figura 1 são apresentadas as comparações entre os títulos de anticorpos aglutinantes na prova de SAM e os títulos de anticorpos neutralizantes detectados no teste de ICLIV expressos em logaritmo de base 10 para os sorovares Canicola e Kennewicki dos pools de soros dos hamsters vacinados com a bacterina A antileptospirose e suas concentrações.

Todos os pools de soros dos hamsters vacinados com a bacterina B pura ou com as suas diluições, submetidos ao teste de inibição de crescimento de leptospiras in vitro, foram não reagentes ao teste de SAM para os sorovares Canicola e Kennewicki e somente os dois pools de soros de hamsters vacinados com a bacterina $\mathrm{A}$ pura foram reagentes $(2 / 20)$ para os sorovares Canicola e Kennewicki, com títulos que variaram de 200 a 400.

As Figuras 2, 3 e 4 apresentam os resultados das comparações entre o teste oficial de potência de bacterinas antileptospiras e o teste de ICLIV, de modo a se estabelecer um limiar entre anticorpos neutralizantes em hamsteres vacinados com bacterinas antilep-

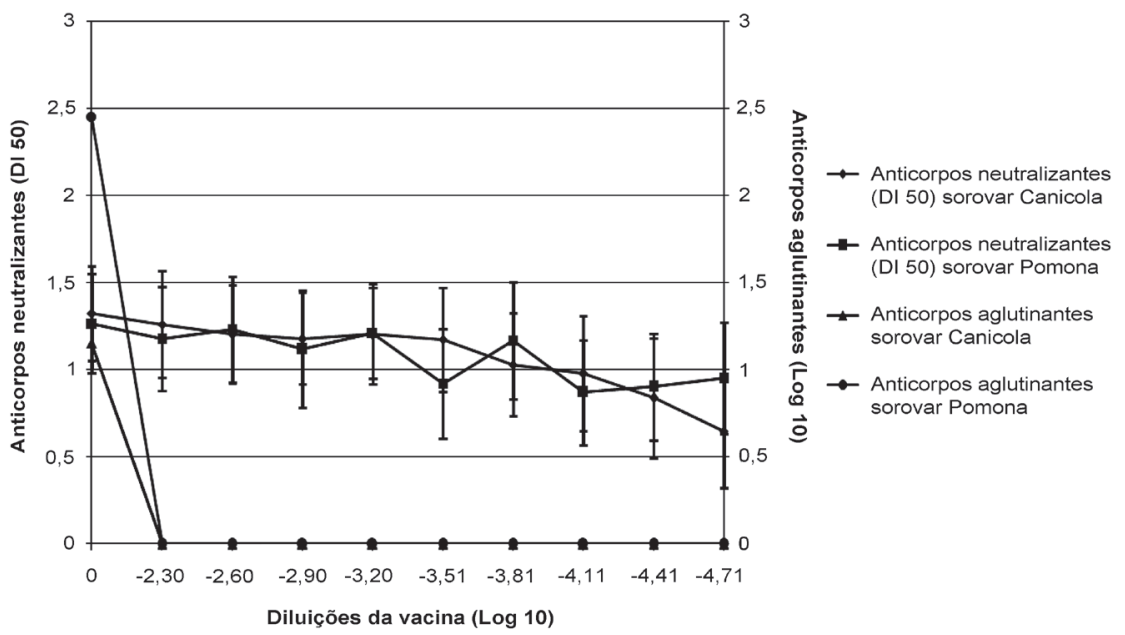

Figura 1 - Associação entre os títulos de anticorpos aglutinantes e os títulos de anticorpos neutralizantes expressos em logaritmo de base 10 para os sorovares Canicola e Kennewicki dos pools de soros dos hamsters imunizados com a bacterina A antileptospirose e suas diluições - São Paulo - 2013

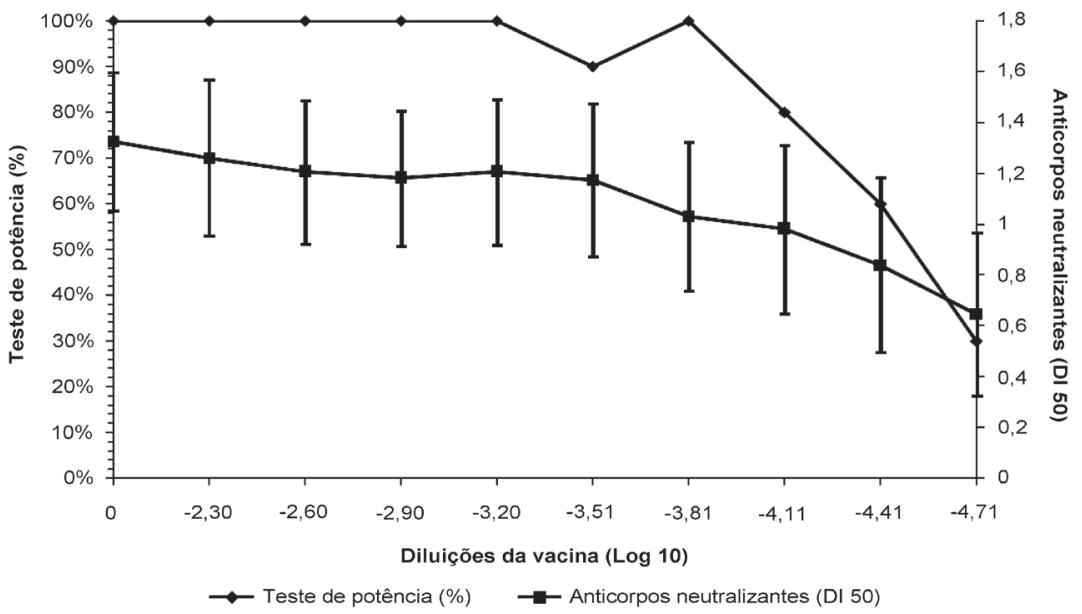

Figura 2 - Associação entre os resultados para o sorovar Canicola do teste de potência em hamsters da bacterina A antileptospirose e os do teste de inibição de crescimento de leptospiras in vitro, segundo a diluição da bacterina expressa em logaritmo de base 10 - São Paulo - 2013 


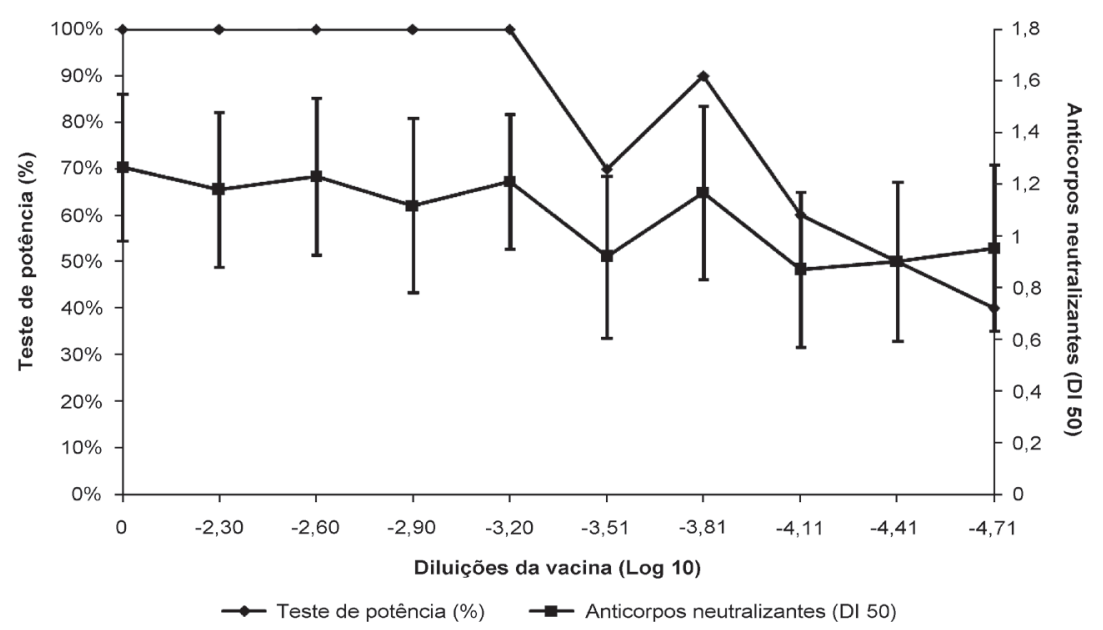

Figura 3 - Associação entre os resultados para o sorovar Kennewicki do teste de potência em hamsters da bacterina A antileptospirose e os do teste de inibição de crescimento de leptospiras in vitro, segundo a diluição da bacterina expressa em logaritmo de base 10 - São Paulo - 2013

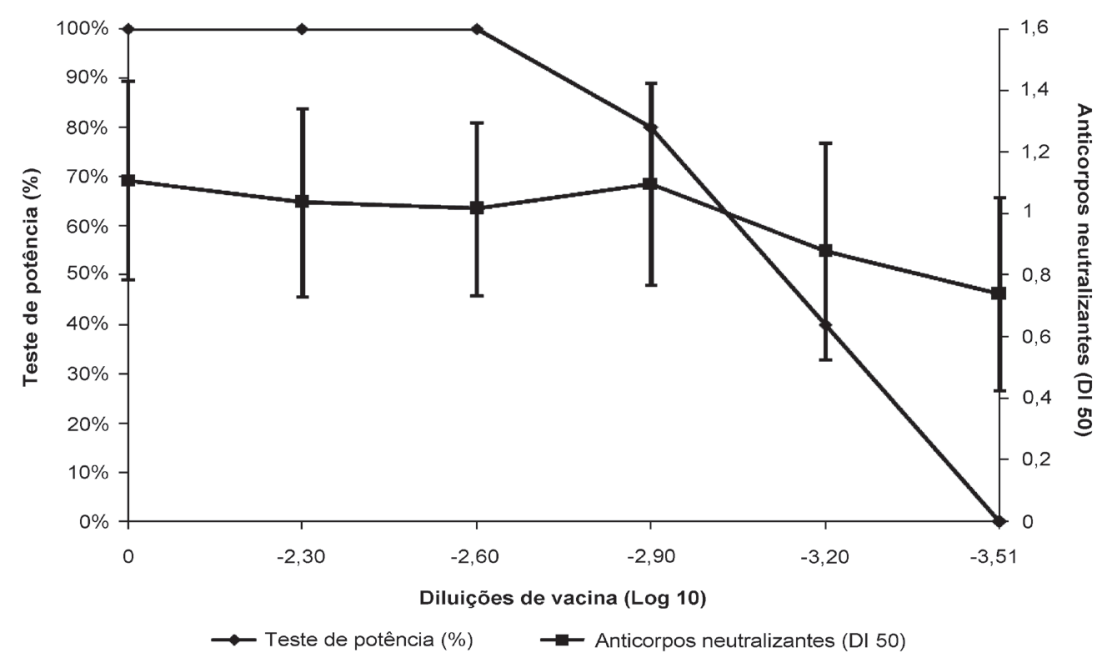

Figura 4 - Associação entre os resultados para o sorovar Canicola do teste de potência em hamsters da bacterina $B$ antileptospirose e os do teste de inibição de crescimento de leptospiras in vitro, segundo a diluição da bacterina expressa em logaritmo de base 10 - São Paulo - 2013

tospirose que corresponda ao nível de aprovação no teste de potência que permita validar a qualidade da bacterina antileptospirose.

\section{Discussão}

Apesar de não estar previsto no protocolo internacional de avaliação de bacterinas comerciais antileptospiras, neste experimento foram utilizadas diferentes diluições das bacterinas, para que fosse possível o estabelecimento do limiar de anticorpos neutralizantes em hamsters imunizados com vacinas antileptos- pirose que correspondesse ao nível de aprovação no teste de potência. Foi demonstrado que as vacinas mais concentradas apresentaram melhores resultados tanto no teste de desafio quanto no teste de ICLIV, tanto para o sorovar Canicola como para o Kennewicki. Esses resultados indicaram que uma maior massa antigênica poderia induzir a uma maior produção de anticorpos e, consequentemente proteção. Resultados semelhantes a esses também foram observados por Favero et al. (1997) quando imunizaram três grupos de bovinos com bacterinas antileptospirose contendo 
os sorovares Icterohaemorrhagiae, Pomona, Hardjo e Wolffi com concentrações de leptospiras variando de $9,8 \times 10^{5}$ a $13,2 \times 10^{7}$ por mililitro.

As proporções de hamsters vacinados sobreviventes ao desafio e caracterizados como portadores renais no $21^{\circ}$ d.p.i., apresentados na Tabela 2 , indicam que as duas bacterinas antileptospirose testadas foram aprovadas na diluição 1:800 recomendada pelas normas internacionais, mas esta diluição não foi capaz de proteger todos os animais contra o estado de portador renal de leptospiras, pois a partir da diluição 1:400 houve a presença de portadores renais para as duas bacterinas usadas. Bey e Johnson (1982) e Bolin et al. (1989) relataram que bacterinas antileptospirose podem proteger contra o estabelecimento da doença, porém algumas vezes não conseguem impedir a infecção e o estabelecimento do estado de portador renal de leptospiras, o que pode ser de grande importância epidemiológica.

A soroaglutinação microscópica realizada nos pools de soros dos hamsteres apresentou ausência de anticorpos aglutinantes para a bacterina $\mathrm{B}$. A bacterina $\mathrm{A}$ induziu a produção de anticorpos aglutinantes contra os sorovares Canicola e Kennewicki, porém apenas quando não diluída.

Os níveis de anticorpos neutralizantes pós-vacinais, apresentados na Figura 1, demonstraram a ausência da correlação entre anticorpos aglutinantes e neutralizantes, como também foi obtido por Soto et al. (2008) e Nardi Junior et al. (2010). Nos animais dos grupos controles não foram detectados anticorpos aglutinantes ou neutralizantes; de fato estes animais foram inoculados apenas com solução salina $0,85 \%$. Assim, os resultados obtidos confirmam a especificidade dos dois testes executados.

Para a avaliação do teste de ICLIV, proposto como uma alternativa para o controle da eficácia de bacterinas antileptospirose, foram comparados os resultados obtidos no teste de potência com desafio em hamster e no teste de ICLIV (Figuras 2, 3 e 4).

Com base nos resultados apresentados nas figuras 2 e 3, a bacterina A, diluída 1:800 da dose recomenda- da para suínos, foi aprovada no teste de potência com desafio em hamsters e induziu títulos de anticorpos neutralizantes na faixa de 0,91 a 1,44 log e de 0,78 a 1,45 log, respectivamente para os sorovares Canicola e Kennewicki, destacando-se que o número de sobreviventes ainda esteve dentro dos critérios mínimos exigidos para aprovação (8/10) mesmo nas diluições de 1:1.600 e 1:12.800, quando desafiada, respectivamente, com os sorovares Kennewicki e Canicola. As diluições 1:1.600 e 1:12.800 foram capazes de induzir títulos de anticorpos neutralizantes na faixa de 0,95 a $1,47 \log$ e de 0,64 a $1,31 \mathrm{log}$, respectivamente.

Os resultados da comparação do teste de potência e de ICLIV referentes à bacterina $B$, apresentados na figura 4, demonstraram que a bacterina diluída 1:800 induziu títulos de anticorpos neutralizantes na faixa de 0,77 a $1,42 \log$.

O valor mínimo dos títulos de anticorpos neutralizantes obtido no teste de ICLIV, em que a proporção de hamsters sobreviventes ao teste de desafio na diluição de 1:800 esteve dentro dos parâmetros exigidos pelos critérios de eficácia de bacterina antileptospirose, foi de 1,09 log, para a bacterina B, com intervalo de confiança (95\%) variando de 0,77 a 1,42 log.

A análise da comparação do desempenho das bacterinas A e B para os sorovares Canicola e Kenewicki, segundo sua concentração, por meio das proporções de animais sobreviventes ao teste de desafio e a média dos títulos de anticorpos neutralizantes dos pools dos soros dos hamsteres, demonstra que títulos de anticorpos neutralizantes iguais ou superiores a 0,77 log correspondem ao nível de aprovação de bacterinas no teste de potência em desafio em hamsteres.

\section{Conclusão}

Nas condições em que foi realizado o presente trabalho, os resultados obtidos possibilitaram o estabelecimento de um limiar de anticorpos neutralizantes que correspondeu ao nível de aprovação no teste de potência e assim validou a qualidade das bacterinas antileptospirose, sem a necessidade do emprego do 
teste de desafio em hamsters. O emprego dessa metodologia com as próprias espécies animais a que se destinam as bacterinas poderá vir a oferecer uma nova proposta de avaliação de bacterinas antileptospirose que dispense o uso de animais de laboratório, o que concorda com a tendência atual de redução do uso de animais em ensaios experimentais (PETROIANU, 1996; FAGUNDES; TAHA, 2004).

\section{Agradecimento}

À Fundação de Amparo a Pesquisa do Estado de São Paulo (FAPESP) pelo apoio financeiro.

\section{Referências}

ALVES, C. J.; VASCONCELlOS, S. A.; CAMARGO, C. R. A.; MORAIS, Z. M. Influência de fatores ambientais na proporção de caprinos soro-reagentes para a leptospirose em cinco centros de criação do Estado da Paraíba. Arquivos do Instituto Biológico, v. 63, n. 2, p. 11-18, 1996.

ARDUINO, G. G. C.; GIRIO, R. J. S.; FREIRE, M. M.; MARCHIORI FILHO, M. Anticorpos contra Leptospira spp. em bovinos leiteiros vacinados com bacterina polivalente comercial. Perfil sorológico frente a dois esquemas de vacinação. Ciência Rural, v. 34, n. 3, p. 865-871, 2004

BEY, R. F.; JOHNSON, R. C. Immunogenicity and humoral and cell-mediated immune response to leptospiral whole cell, outer envelope, and protoplasmic cylinder vaccines in hamsters and dogs. American Journal of Veterinary Research, v. 43, n. 5, p. 835-840, 1982

BOLIN, C. A.; THIERMANN, A. B.; HANDSAKER, A. L.; FOLEY, J. W. Effect of vaccination with a pentavalent leptospiral vaccine on Leptospira interrogans serovar hardjo type hardjo bovis infection of pregnant catlle. American Journal of Veterinary Research, v. 50, n. 1, p. 161-165, 1989.

COELHO, W. A. S.; VASCONCELLOS, S. A.; MORAIS, Z. M.; IKUTA, C. Y.; GONCALES, A. P.; SOUZA, G. O.; DIB, C. C.; SOTO, F. R. M. Canine anti-leptospira bacterins commercialized in Brazil: a challenge made with indigenous strains of serovars Canicola and Copenhageni. Scientia Vitae, v. 1, n. 1, p. 3-11, 2013.

FAGUNDES, D. J.; TAHA, M. O. Modelo animal de doença: critérios de escolha e espécies de animais de uso corrente. Acta Cirurgica Brasileira, v. 19, n. 1, p. 59-65, 2004.

FAINE, S.; ADLER, B.; BOLIN, C.; PEROLAT, P. Leptospira and leptospirosis. 2. ed. Melbourne: MediSci, 1999. 272 p.

FAVERO, A. C. M.; MANGERONA, A. C. S.; ALESSI, L. J.; MORAIS, Z. M.; PINHEIRO, S. R.; FERREIRA NETO, J. S.; VASCONCELLOS, S. A. Aglutininas pós-vacinais em bovinos imunizados com bacterina tetravalente contra a leptospirose. Influência de reações pré-vacinais, homólogas e heterólogas. Arquivos do Instituto Biológico, v. 64, n. 2, p. 45-55, 1997.

HANSON, L. E. Immunology of bacterial diseases, with special reference to leptospirosis. Journal of the American Veterinary Medical Association, v. 170, n. 9, p. 991-994, 1977.

LEVETT, P. N. Leptospirosis. Clinical Microbiology Veterinary, v. 14, n. 2, p. 296-326, 2001.

MARBEHANT, P. Leptospiral vaccines batch potency testing. European monograph status review. Pharmeuropa, v. 99, n. 2, p. 11-16, 1999.

MYERS, D. M. Manual de métodos para el diagnóstico de laboratório de la leptospirosis. Martinez: OPAS, Centro Panamericano de Zoonosis, 1985.

NARDI JUNIOR, G.; GENOVEZ, M. E.; RIBEIRO, M. G.; CASTRO, V.; JORGE, A. M. An in vitro growth inhibition test for measuring the potency of Leptospira spp. Sejroe group vaccine in buffaloes. Biologicals, v. 38, n. 4, p. 474-478, 2010.

OFFICE INTERNATIONAL DES EPIZOOTIES - OIE. World
Organisation for Animal Health. Leptospirosis. In: Manual of diagnostic tests and vaccines for terrestrial animals. Paris: Office International des Epizooties, 2008. chap. 2.1.9, p. 255-258,

PETROiAnU, A. Aspectos éticos na pesquisa em animais. Acta Cirurgica Brasileira, v. 11, n. 3, p. 157-164, 1996.

PIZZI, M. Sampling variation of the fifty percent end-point, determined by Reed-Muench (Behrens) method. Human Biology, v. 22, n. 3, p. 151-190, 1950.

REED, L. J.; MUENCH, H. A simple method of estimating fifty per cent endpoints. American Journal of Hygiene, v. 27, n. 3, p. 493-497, 1938

RODRIGUES, M. A.; VASCONCELLOS, S. A.; GONÇALES, A. P.; MORAIS, Z. M.; SOUZA, G. O.; HAGIWARA, M. K. Anticorpos revelados pelo teste de inibição do crescimento de leptospiras in vitro (TICL) contra os sorovares Canicola, Icterohaemorrhagiae e Copenhageni em cães adultos revacinados anualmente com vacina comercial contendo bacterinas dos sorovares Canicola, Icterohaemorrhagiae, Grippotyphosa e Pomona. Pesquisa Veterinária Brasileira, v. 33, n. 5, p. 627-634, 2013.

SOTO, F. R. M.; PINHEIRO, S. R.; MORAIS, Z. M.; GONCALES, A. P.; AZEVEDO, S. S.; BERNARDI, F.; CAMARGO, S. R.; VASCONCELLOS, S. A. Comparison of agglutinating and neutralizing antibodies to serovar hardjo in sows immunized with two commercial whole culture polivalent anti-leptospira bacterins. Brazilian Journal of Microbiology, v. 39, n. 3, p. 484488, 2008.

TABATA, R.; SCANAVINI NETO, H.; ZUANAZE, M. A. F.; OLIVEIRA, E. M. D.; DIAS, R. A.; MORAIS, Z. M.; ITO, F. H.; VASCONCELLOS, S. A. Cross neutralizing antibodies in hamsters vaccinated with leptospiral bacterins produced with three serovars of Serogroup Sejroe. Brazilian Journal of Microbiology, v. 33, n. 3, p. 267-270, 2002.

TRIPATHY, D. N.; HANSON, L. E.; KRUMREY, W. A. An in vitro growth inhition test for leptospiral neutralization. In: ANNUAL MEETING OF THE UNITED STATES ANIMAL HEALTH ASSOCIATION, 75., 1971, St. Louis. Proceedings... St. Louis: Animal Health Association, 1971. p. 138-143.

TRIPATHY, D. N.; HANSON, L. E.; MANSFIELD, M. E. Growth inhibition test for measurement of immune response of animals with leptospiral bacterins. In: ANNUAL MEETING OF THE UNITED STATES ANIMAL HELTH ASSOCIATION, 77., 1973, St. Louis. Proceedings... St Louis: Animal Health Association, 1973. p. 113-118.

UNITED STATES OF AMERICA. Department of Agriculture. Leptospira Pomona bacterin. Washington, DC: Office of the Federal Register National Archives and Records Administration, 2006a. chap. 1, pt. 113, sec. 113.101, p. 656. (Code Federal Regulation).

UNITED STATES OF AMERICA. Department of Agriculture. CFR 113.103 Leptospira Pomona bacterin. Washington, DC: Office of the Federal Register National Archives and Records Administration, 2006b. chap. 1, pt. 113, sec. 113.103, p. 657. (Code Federal Regulation). 